\title{
Effects of Yarrowia lipolytica supplementation on growth performance, intestinal health and apparent ileal digestibility of diets fed to nursery pigs
}

\author{
Yi-Chi Cheng ${ }^{1}$, Marcos Elias Duarte ${ }^{1}$, and Sung Woo Kim ${ }^{1 / *}$
}

\author{
* Corresponding Author: Sung Woo Kim \\ Tel: +1-919-513-1494, Fax: +1-919-515-6884, \\ E-mail: sungwoo_kim@ncsu.edu \\ ${ }^{1}$ Department of Animal Science, North \\ Carolina State University, Raleigh, NC 27695, \\ USA \\ ORCID \\ Yi-Chi Cheng \\ https://orcid.org/0000-0002-4845-9721 \\ Marcos Elias Duarte \\ https://orcid.org/0000-0003-0094-336X \\ Sung Woo Kim \\ https://orcid.org/0000-0003-4591-1943
}

Submitted Aug 18, 2021; Revised Sept 3, 2021; Accepted Sept 23, 2021

\begin{abstract}
Objective: The objective was to evaluate the efficacy of increasing supplementation of Yarrowia lipolytica (YL) up to $3.0 \%$ replacing $1.6 \%$ poultry fat and $0.9 \%$ blood plasma for growth performance, intestinal health and nutrient digestibility of diets fed to nursery pigs.

Methods: Twenty-four pigs weaned at $24 \mathrm{~d}$ of age (initial body weight at $7.2 \pm 0.6 \mathrm{~kg}$ ) were allotted to three dietary treatments $(\mathrm{n}=8)$ based on the randomized complete block. The diets with supplementation of YL $(0.0 \%, 1.5 \%$, and $3.0 \%$, replacing poultry fat and blood plasma up to $1.6 \%$ and $0.9 \%$, respectively) were fed for $21 \mathrm{~d}$. Feed intake and body weight were recorded at d 0, 10, and 21. Fecal score was recorded at every odd day from d 3 to 19. Pigs were euthanized on d 21 to collect proximal and distal jejunal mucosa to measure intestinal health markers including tumor necrosis factor-alpha, interleukin-8, immunoglobulin A and immunoglobulin G. Ileal digesta was collected for apparent ileal digestibility (AID) of nutrients in diets. Data were analyzed using Proc Mixed of SAS.

Results: Supplementation of YL (1.5\% and 3.0\%) replacing poultry fat and blood plasma did not affect growth performance, fecal score and intestinal health. Supplementation of YL at 1.5\% did not affect nutrient digestibility, whereas supplementation of YL at 3.0\% reduced AID of dry matter ( $40.2 \%$ to $55.0 \%)$, gross energy ( $44.0 \%$ to $57.5 \%)$, crude protein $(52.1 \%$ to $66.1 \%)$, and ether extract (50.8\% to $66.9 \%)$ compared to diets without supplementation.

Conclusion: Yarrowia lipolytica can be supplemented at 1.5\% in nursery diets, replacing $0.8 \%$ poultry fat and $0.45 \%$ blood plasma without affecting growth performance, intestinal health and nutrient digestibility. Supplementation of YL at 3.0\% replacing 1.6\% poultry fat and $0.9 \%$ blood plasma did not affect growth performance and intestinal health, whereas nutrient digestibility was reduced.
\end{abstract}

Keywords: Apparent Ileal Digestibility; Growth Performance; Intestinal Health; Nursery Pigs; Yarrowia lipolytica; Yeast

\section{INTRODUCTION}

Animal fats and plant oils have been used in swine diets in order to improve dietary energy digestibility [1], growth and feed efficiency [2]. Fatty acids (FA) play important roles in cell-signaling, immune function and cell membrane integrity [3]. In addition, FA can be divided into two main groups comprised of saturated FA and unsaturated FA. The quantities of FA vary greatly, depending on the sources (Table 1). Unsaturated FA improves the animal health and meat quality by enhancing intestinal barrier functions [4] and altering the pork fat composition [5], respectively.

The production of animal fats was increased by 15\% from 2013 to 2020 in the USA [6]. Other than animal fats, the production of plant oils, including soybean oil, seed oils, palm 
Table 1. The nutrient composition of Yarrowia lipolytica and common fat supplements [23]

\begin{tabular}{lc}
\hline Items & Yarrowia lipolytica ${ }^{1)}$ \\
\hline Gross energy (kcal/kg) & 7,996 \\
FA $^{2)}$ in EE (\%) & \\
Myristic acid, C14:0 & 0.1 \\
Palmitic acid, C16:0 & 12.5 \\
Palmitoleic acid, C16:1 & 4.0 \\
Stearic acid, C18:0 & 16.1 \\
Oleic acid, C18:1 & 52.3 \\
Linoleic acid, C18:2n6 & 9.6 \\
DHA, C22:6n3 & 2.7 \\
Unsaturated FA in total fat & 68.8 \\
Crude protein (\%) & 9.7 \\
Amino acids (\%) & \\
Histidine & \\
Isoleucine & 0.25 \\
Leucine & 0.40 \\
Lysine & 0.71 \\
Methionine & 0.62 \\
Phenylalanine & 0.14 \\
Threonine & 0.39 \\
Tryptophan & 0.42 \\
Valine & 0.15 \\
\hline
\end{tabular}

FA, fatty acids; $E E$, ether extract; $\mathrm{DHA}$, docosahexaenoic acid.

1) Yarrowia lipolytica contain $9.7 \% \mathrm{CP}$ and $72.7 \%$ fat in the total yeast.

2) Based on analyzed composition using gas chromatography/mass spectrometry (GC/MS) method.

${ }^{3)}$ Amino acid profile is based on Michalik et al [24].

oil and coconut oil, was increased by $22 \%$ from 172 to 209 million tons globally during the same period [6]. However, animal fats and plant oils have also been largely used in different industry sectors, including biodiesel and food industries [7]. For the bioenergy production, the global demand of fats and oils has been increased by $38 \%$ in the last decade [8] and the food industry requires higher fat quality than the feed industry. Therefore, fats with lower quality, such as restaurant grease and animal-vegetable blend oils are commonly used in animal production in the USA. These fat by-products could have higher peroxidation possibly with negative impacts on intestinal health and growth performance of animals [9]. Due to these concerns, alternative fat supplements have been sought, including oleaginous microorganisms [10] and insect oils [11].

Oleaginous microorganisms include yeasts, bacteria and microalgae rich in oil and these are also called single cell oils (SCO). Depending on the sources, SCO contain FAs with unique profiles different from conventional fats and oils, proteins from cell wall with unique functions and other organic compounds such as vitamins [12]. Recently SCO have been used in aquaculture to replace conventional fats without adverse effects on fish growth and fish quality [13]. Yarrowia lipolytica is one of oleaginous yeasts and generally recognized as safe in food industry [14]. The strain of Yarrowia lipolytica used in this study contains $72.7 \%$ of fat and high concentration (52.3\%) of oleic acid (Table 1). Oleic acid has been shown to reduce oxidative stress and inflammatory response by activating peroxisome proliferator activated receptor in animals [15]. Previous studies showed that animal fats and plant oils are $80 \%$ digestible by weaned pigs [1]. Similar to Yarrowia lipolytica, restaurant grease has similar oleic acid content, however, its high peroxidation rate compromises its benefits [9].

In general, $\beta$-glucans, including 1,3 and 1,6 $\beta$-glucans, are the major components of the yeast cell wall (55\% to 65\%) [16]. The second major component from the yeast cell wall is mannoprotein (30\% to $40 \%$ ), which is glycoprotein mainly containing mannans on the external surface of the wall [17]. Beta-glucans and mannans are bioactive compounds from yeast cell walls with potential benefits on the development of intestinal immune system of animals $[18,19]$ that can be similar to the role of functional compounds in blood plasma. Blood plasma has long been used in swine industry in order to improve growth performance [20] of nursery pigs by enhanced intestinal health that reduces inflammatory activation and promotes the intestinal barrier function [21]. Otherwise, $\beta$-glucans and mannans from yeast cell wall also have beneficial effects on intestinal health by mitigating the release of pro-inflammatory cytokines and preventing the colonization of pathogens on intestinal mucosa $[18,19]$.

Therefore, the hypothesis was that Yarrowia lipolytica can be used as a fat supplement in nursery diets providing bioactive components, including oleic acid, $\beta$-glucans and mannans to enhance intestinal health, nutrient digestibility and growth performance of nursery pigs. To test the hypothesis, the objective was to evaluate the efficacy of increasing supplementation of Yarrowia lipolytica up to 3.0\% replacing $1.6 \%$ poultry fat and $0.9 \%$ blood plasma for growth, intestinal health and digestibility of nutrients in diets fed to nursery pigs.

\section{MATERIALS AND METHODS}

\section{Animal care}

The experimental protocol was approved by the Institutional Animal Care and Use Committee of North Carolina State University.

\section{Animal, design and diets}

Twenty-four newly weaned pigs at $24 \mathrm{~d}$ of age with initial body weight $(\mathrm{BW})$ of $7.2 \pm 0.6 \mathrm{~kg}$ were allotted to three dietary treatments $(n=8)$ based on the randomized complete block design. Initial BW (light and heavy) and sex (gilts and barrows) were considered as blocks following Holanda et al [22]. Pigs were housed in pens individually. The dietary treatments consisted of a basal diet supplemented with Yarrowia lipolytica (CJ Bio; Fort Dodge, IA, USA) at three 
levels $(0.0 \%, 1.5 \%$, and $3.0 \%$ of Yarrowia lipolytica as YL0, YL1.5, and YL3, respectively). Yarrowia lipolytica was supplemented at $1.5 \%$ and $3.0 \%$, replacing poultry fat $(0.8 \%$ and $1.6 \%$, respectively) and blood plasma $(0.45 \%$ and $0.9 \%$, respectively) balancing metabolizable energy and standardized ileal digestible Lys in phase 1 and phase 2 diets. The nutrient compositions of Yarrowia lipolytica and experimental diets are shown in Table 1 and 2, respectively. All experimental diets were formulated to meet or exceed the nutrient requirements suggested by NRC [23] and fed to pigs for $21 \mathrm{~d}$ divided into two phases: phase 1 ( $\mathrm{d} 0$ to 10 ) and phase 2 ( $\mathrm{d} 10$ to 21 ). Titanium dioxide at $0.4 \%$ was added in diets as an indigestible external marker during the last 7 $\mathrm{d}$ of experiment.

\section{Growth performance and fecal score}

Body weight and feed intake were recorded at $\mathrm{d} 0,10$, and 21 to calculate average BW, average daily gain (ADG), average daily feed intake (ADFI), and gain to feed ratio (G:F). Fecal scores from every pig were recorded every odd day using a 1 to 5 scale: i) very hard and dry stool, ii) firm stool, iii) normal stool, iv) loose stool, and v) watery stool with no shape following Guo et al [25].

Table 2. Feed formulation and nutrient composition of diets with Yarrowia lipolytica

\begin{tabular}{|c|c|c|c|c|c|c|}
\hline \multirow{2}{*}{ Ingredient } & \multicolumn{3}{|c|}{ Phase 1) } & \multicolumn{3}{|c|}{ Phase $2^{1)}$} \\
\hline & YLO & YL1.5 & YL3 & YLO & YL1.5 & YL3 \\
\hline \multicolumn{7}{|l|}{ Feedstuff (\%) } \\
\hline Yellow dent corn, ground & 42.8 & 42.5 & 42.2 & 49.7 & 49.3 & 49.0 \\
\hline Whey permeate & 24.0 & 24.0 & 24.0 & 15.0 & 15.0 & 15.0 \\
\hline Soybean meal, 48\% CP & 20.0 & 20.0 & 20.0 & 23.0 & 23.0 & 23.0 \\
\hline Poultry meal & 3.00 & 3.00 & 3.00 & 3.00 & 3.00 & 3.00 \\
\hline Fish meal & 2.00 & 2.00 & 2.00 & 0.00 & 0.00 & 0.00 \\
\hline Yarrowia lipolytica & 0.00 & 1.50 & 3.00 & 0.00 & 1.50 & 3.00 \\
\hline Poultry fat & 2.15 & 1.36 & 0.57 & 1.98 & 1.19 & 0.40 \\
\hline Blood plasma & 2.90 & 2.45 & 2.00 & 4.10 & 3.65 & 3.20 \\
\hline L-lysine $\mathrm{HCl}$ & 0.72 & 0.75 & 0.77 & 0.43 & 0.46 & 0.48 \\
\hline DL-methionine & 0.31 & 0.33 & 0.33 & 0.18 & 0.20 & 0.20 \\
\hline L-threonine & 0.27 & 0.28 & 0.29 & 0.12 & 0.13 & 0.14 \\
\hline L-tryptophan & 0.05 & 0.06 & 0.06 & 0.00 & 0.01 & 0.01 \\
\hline Salt & 0.25 & 0.25 & 0.25 & 0.25 & 0.25 & 0.25 \\
\hline Dicalcium phosphate & 0.65 & 0.65 & 0.65 & 0.85 & 0.85 & 0.85 \\
\hline Limestone & 0.70 & 0.70 & 0.70 & 0.85 & 0.85 & 0.85 \\
\hline Vitamin premix ${ }^{2)}$ & 0.03 & 0.03 & 0.03 & 0.03 & 0.03 & 0.03 \\
\hline Mineral premix ${ }^{3)}$ & 0.15 & 0.15 & 0.15 & 0.15 & 0.15 & 0.15 \\
\hline Titanium dioxide & 0.00 & 0.00 & 0.00 & 0.40 & 0.40 & 0.40 \\
\hline \multicolumn{7}{|l|}{ Calculated composition } \\
\hline DM (\%) & 90.6 & 90.7 & 90.8 & 90.2 & 90.3 & 90.3 \\
\hline $\mathrm{ME}(\mathrm{kcal} / \mathrm{kg})$ & 3,401 & 3,401 & 3,401 & 3,401 & 3,401 & 3,401 \\
\hline $\mathrm{CP}(\%)$ & 20.3 & 20.0 & 19.6 & 21.1 & 20.9 & 20.5 \\
\hline SID lysine (\%) & 1.50 & 1.50 & 1.50 & 1.35 & 1.35 & 1.35 \\
\hline SID methionine+cysteine (\%) & 0.83 & 0.84 & 0.83 & 0.74 & 0.76 & 0.74 \\
\hline SID tryptophan (\%) & 0.25 & 0.26 & 0.25 & 0.23 & 0.24 & 0.23 \\
\hline SID threonine (\%) & 0.88 & 0.88 & 0.88 & 0.79 & 0.79 & 0.79 \\
\hline $\mathrm{Ca}(\%)$ & 0.85 & 0.85 & 0.85 & 0.80 & 0.81 & 0.80 \\
\hline STTD P (\%) & 0.46 & 0.46 & 0.45 & 0.42 & 0.42 & 0.41 \\
\hline \multicolumn{7}{|l|}{ Analyzed composition (\%) } \\
\hline $\mathrm{DM}$ & 90.4 & 90.3 & 90.4 & 90.4 & 89.7 & 90.2 \\
\hline $\mathrm{CP}$ & 22.36 & 21.87 & 22.34 & 22.69 & 23.35 & 23.00 \\
\hline EE & 4.68 & 4.54 & 4.49 & 4.90 & 4.47 & 4.48 \\
\hline
\end{tabular}

CP, crude protein; DM, dry matter; ME, metabolizable energy; SID, standardized ileal digestible; STTD, standardized total tract digestible; EE, ether extract.

1) The dietary treatments consisted of a basal diet supplemented with Yarrowia lipolytica at $0.0 \%, 1.5 \%$, and 3.0\% as YL0, YL1.5 and YL3, respectively.

2) The vitamin premix provided the following per kilogram of complete diet: 6,613.8 IU of vitamin A as vitamin A acetate, $992.0 \mathrm{IU}$ of vitamin $\mathrm{D}_{3}, 19.8 \mathrm{IU}$ of vitamin E, $2.64 \mathrm{mg}$ of vitamin $\mathrm{K}$ as menadione sodium bisulfate, $0.03 \mathrm{mg}$ of vitamin $\mathrm{B}_{12}, 4.63 \mathrm{mg}$ of riboflavin, $18.52 \mathrm{mg}$ of D-pantothenic acid as calcium pantothenate, $26.45 \mathrm{mg}$ of niacin and $0.07 \mathrm{mg}$ of biotin.

${ }^{3)}$ The trace mineral premix provides the following per kilogram of complete diet: $33.0 \mathrm{mg} \mathrm{Mn}$ as manganous oxide, $109.5 \mathrm{mg}$ of Fe as ferrous sulfate, 109.5 $\mathrm{mg}$ of $\mathrm{Zn}$ as zinc sulfate, $16.5 \mathrm{mg}$ of $\mathrm{Cu}$ as copper sulfate, $0.3 \mathrm{mg}$ of I as ethylenediamine dihydroiodide and $0.3 \mathrm{mg}$ of Se as sodium selenite. 


\section{Sample collection and processing}

After $21 \mathrm{~d}$ of feeding, all pigs were euthanized by the penetration of a captive bolt to the head following by exsanguination in order to collect samples. Sections of proximal $(1.5 \mathrm{~m}$ after the pyloric duodenal junction) and distal ( $1.5 \mathrm{~m}$ before the ileocecal junction) jejunum were collected and rinsed with $0.9 \%$ saline solution. The jejunal mucosa was collected into $2 \mathrm{~mL}$ microcentrifuge tubes and immediately frozen in liquid nitrogen and then stored at $-80^{\circ} \mathrm{C}$ for immune status measurements. Ileal digesta was collected into $150 \mathrm{~mL}$ containers placed on ice and then stored at $-20^{\circ} \mathrm{C}$ for apparent ileal digestibility (AID).

Jejunal mucosa samples $(1 \mathrm{~g})$ from the $2 \mathrm{~mL}$ microcentrifuge tubes were taken and added with $1 \mathrm{~mL}$ of phosphatebuffered saline solution into $5 \mathrm{~mL}$ polypropylene tubes. Mucosa samples were homogenized using a tissue homogenizer (Tissuemiser, Thermo Fisher Scientific Inc., Rockford, IL, USA) for $30 \mathrm{~s}$ on ice and transferred to a new $2 \mathrm{~mL}$ microcentrifuge tube for centrifugation for $15 \mathrm{~min}$ at $14,000 \times \mathrm{g}$ (MiniSpin plus; Eppendorf AG, Hamburg, Germany) as described by Holanda et al [22]. The supernatant was divided into 6 sets of $0.15 \mathrm{~mL}$ into polypropylene tubes and stored at $-80^{\circ} \mathrm{C}$ for further analysis.

\section{Intestinal health makers}

The concentrations of total protein, tumor necrosis factoralpha (TNF- $\alpha$ ), interleukin-8 (IL-8), immunoglobulin A (IgA), and immunoglobulin $\mathrm{G}(\operatorname{IgG})$ in proximal and distal jejunal mucosa were analyzed by the colorimetric method and the absorbance was measured on a plate reader (Synergy HT; BioTek Instruments, Winooski, VT, USA).

The concentration of total protein was analyzed using Pierce BCA Protein Assay Kit (\#23225; Thermo Fisher Scientific, USA) as described by Holanda et al [22]. Mucosa samples were diluted (1:50) to reach the working range of 20 to $2,000 \mu \mathrm{g} / \mathrm{mL}$. The absorbance was measured at $562 \mathrm{~nm}$. The concentration of total protein was calculated by the standard curve and used to normalize the concentrations of TNFa, IL-8, IgA, and IgG.

The concentration of TNF- $\alpha$ was analyzed using the Porcine TNF- $\alpha$ Immunoassay Kit (\#PTA00; R\&D Systems, Minneapolis, MN, USA) as described by Duarte et al [26]. The working range of standards was 0 to $1,500 \mathrm{pg} / \mathrm{mL}$. The absorbance was measured at $450 \mathrm{~nm}$ and corrected with 570 $\mathrm{nm}$. The concentration of TNF- $\alpha$ was calculated by the standard curve and described as $\mathrm{pg} / \mathrm{mg}$ of protein.

The concentration of IL-8 was analyzed using the Porcine IL-8/CXCL8 Immunoassay Kit (\#P8000; R\&D Systems, USA) following Moita et al [27]. Mucosa samples were diluted (1:6) to reach the working range of standards from 0 to $4,000 \mathrm{pg} / \mathrm{mL}$. The absorbance was measured at $450 \mathrm{~nm}$ and corrected with $570 \mathrm{~nm}$. The concentration of IL- 8 was calculated by the standard curve and described as ng/mg of protein.

The concentration of IgA was analyzed using the pig ELISA kit (\#E101-102; Bethyl Laboratories, Montgomery, TX, USA) following Holanda et al [22]. Mucosa samples were diluted $(1: 1,500)$ to reach the working range of standards from 15.6 to $1,000 \mathrm{ng} / \mathrm{mL}$. The absorbance was measured at $450 \mathrm{~nm}$ and corrected with $540 \mathrm{~nm}$. The concentration of IgA was calculated by the standard curve and described as $\mu \mathrm{g} / \mathrm{mg}$ of protein.

The concentration of IgG was analyzed using the pig ELISA kit (\#E101-104; Bethyl Laboratories, USA) following Duarte et al [26]. Mucosa samples were diluted $(1: 3,600)$ to reach the working range of standards from 7.8 to $500 \mathrm{ng} / \mathrm{mL}$. The absorbance was measured at $450 \mathrm{~nm}$ and corrected with $570 \mathrm{~nm}$. The concentration of IgG was calculated by the standard curve and described as $\mu \mathrm{g} / \mathrm{mg}$ of protein.

\section{Apparent ileal digestibility}

Frozen ileal digesta samples were freeze dried $(24 \mathrm{D} \times 48$, Virtis, Gardiner, NY, USA). Then, phase 2 diets and dried ileal digesta were ground to fine powder form (Method 934.01, AOAC, 2006). The concentration of titanium dioxide in diets and digesta was measured following Myers et al [28]. The dry matter (DM) was measured by following Passos et al [28]. Gross energy (GE) was measured using bomb calorimeter (Parr 6200; Parr instrument company, Moline, IL, USA). The crude protein $(\mathrm{CP})$ was measured in the diets and digesta by using LECO CN-2000 Nitrogen Analyzer (LECO Corporation, St. Joseph, MI, USA) following (AOAC method 990.03) [30]. Ether extract (EE) was measured by using a Soxhlet extraction method (AOAC method 920.39) [30].

Apparent ileal digestibilities of DM, GE, CP, and EE were calculated using the titanium dioxide concentration in diets and digesta following Chen et al [31]. The AID was calculated with the following equation:

$$
\begin{aligned}
\mathrm{AID} \%= & {\left[1-\left(\mathrm{TiO}_{2} \text { in } \operatorname{diet} / \mathrm{TiO}_{2} \text { in digesta }\right)\right.} \\
& \times(\text { nutrient in digesta } / \text { nutrient in diet })] \times 100
\end{aligned}
$$

\section{Statistical analysis}

Data were analyzed using the MIXED procedure in SAS 9.3 (SAS Inc, Cary, NC, USA). Dietary treatments were defined as fixed effects. Initial BW and sex were considered as blocks and defined as random effects. Outliers were defined as data greater than the 75 th percentile $+1.5 \times$ the interquartile range and smaller than the 25 th percentile- $1.5 \times$ the interquartile range and removed from analysis. One pig from treatment YL1.5 was removed for analysis of AID of CP and EE due to insufficient digesta. The least squares mean comparisons with the general linear model procedure was used to calculate mean values for all treatments. The least significant difference test (PDIFF) was used for a pairwise comparison among 
dietary treatments. The analysis of fecal score data was performed by using Kruskal-Wallis Test with Dwass, Steel, Critchlow-Fligner method option for pairwise two-sided multiple comparisons following Guo et al [25]. Statistical significance was $\mathrm{p}<0.05$ and $0.05 \leq \mathrm{p}<0.10$ was considered as a tendency.

\section{RESULTS}

Initial BW was $7.2 \pm 0.6 \mathrm{~kg}$ and did not differ among treatments. Overall ADG, ADFI, and G:F were $252 \pm 37 \mathrm{~g}, 421 \pm 52$ $\mathrm{g}$, and $0.60 \pm 0.04$, respectively and these were not affected by the supplementation of Yarrowia lipolytica at 1.5\% and $3.0 \%$ in diets (Table 3). There were no difference in fecal scores among the treatments (Figure 1). Supplemental Yarrowia lipolytica at $1.5 \%$ and $3.0 \%$ in diets did not affect the concentrations of intestinal immune markers, including TNF- $\alpha(0.67 \pm 0.12$ and $2.15 \pm 0.40 \mathrm{pg} / \mathrm{mg})$, IL-8 $(0.66 \pm 0.07$ and $1.02 \pm 0.22 \mathrm{ng} / \mathrm{mg}), \operatorname{IgA}(1.58 \pm 0.17$ and $1.51 \pm 0.21 \mu \mathrm{g} / \mathrm{mg})$ and $\operatorname{IgG}(4.39 \pm 0.33$ and $4.95 \pm 0.67 \mu \mathrm{g} / \mathrm{mg})$ in proximal and distal jejunal mucosa (Table 4). Pigs fed diets with 3.0\% Yarrowia lipolytica had lower ( $\mathrm{p}<0.05)$ AID of DM $(40.2 \%$ to $55.0 \%$ ), GE (44.0\% to $57.5 \%$ ), and $\mathrm{EE}$ (50.8\% to $66.9 \%)$ than pigs fed diets with $0.0 \%$ Yarrowia lipolytica (Table 5). Pigs fed diets with 3.0\% Yarrowia lipolytica tended to have lower $(\mathrm{p}=0.074)$ AID of CP $(52.1 \%$ to $66.1 \%)$ than pigs fed $0.0 \%$ Yarrowia lipolytica. Pigs fed diets with 1.5\% Yarrowia lipolytica had higher $(\mathrm{p}<0.05)$ AID of GE $(56.5 \%$ to $44.0 \%)$ and $\mathrm{EE}$ (62.3\% to $50.8 \%)$ than pigs fed diets with

Table 3. Growth performance of pigs fed diet with Yarrowia lipolytica

\begin{tabular}{lccccc}
\hline \multirow{2}{*}{ Item } & \multicolumn{3}{c}{ Treatment $^{\text {1) }}$} & \multirow{2}{*}{ SEM } & p-value \\
\cline { 2 - 4 } & YL0 & YL1.5 & YL3 & & \\
\hline BW (kg) & & & & & \\
Initial & 7.1 & 7.2 & 7.2 & 0.6 & 0.979 \\
d 10 & 7.9 & 8.3 & 8.3 & 1.0 & 0.584 \\
d 21 & 12.1 & 12.9 & 12.4 & 1.4 & 0.563 \\
ADG (g) & & & & & \\
d 0 to 10 & 73 & 112 & 113 & 41 & 0.472 \\
d 10 to 21 & 387 & 419 & 370 & 53 & 0.636 \\
Overall & 237 & 273 & 248 & 37 & 0.542 \\
ADFI (g) & & & & & \\
d 0 to 10 & 164 & 186 & 208 & 34 & 0.343 \\
d 10 to 21 & 691 & 616 & 625 & 71 & 0.244 \\
Overall & 433 & 411 & 419 & 52 & 0.741 \\
G:F & & & & & \\
d 0 to 10 & 0.45 & 0.64 & 0.64 & 0.08 & 0.175 \\
d 10 to 21 & 0.56 & 0.68 & 0.63 & 0.04 & 0.104 \\
Overall & 0.55 & 0.66 & 0.59 & 0.04 & 0.165 \\
\hline
\end{tabular}

SEM, standard error of mean; BW, body weight; ADG, average daily gain; $A D F I$, average daily feed intake; G:F, gain to feed ratio.

1) The dietary treatments consisted of a basal diet supplemented with Yarrowia lipolytica at $0.0 \%, 1.5 \%$, and $3.0 \%$ as YLO, YL1.5, and YL3, respectively.

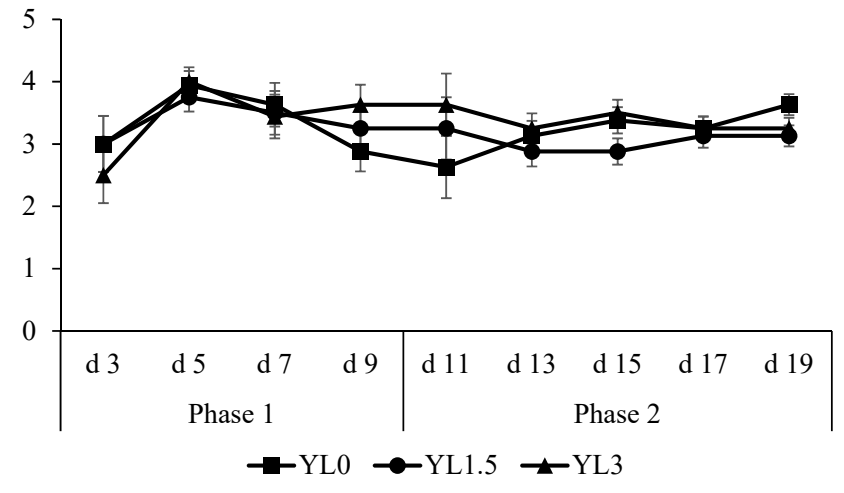

Figure 1. Fecal score of pigs fed diet with Yarrowia lipolytica. Fecal score: (1) very firm stool, (2) normal firm stool, (3) moderately loose stool, (4) loose, watery stool and (5) very watery stool with no shape. The dietary treatments consisted of a basal diet supplemented with Yarrowia lipolytica at 0.0\%, 1.5\%, and 3.0\% as YL0, YL1.5 and YL3, respectively.

3.0\% Yarrowia lipolytica. However, pigs fed diets with 1.5\% Yarrowia lipolytica did not affect AID of DM (52.5\% to 55.0\%), GE (56.5\% to $57.5 \%), \mathrm{CP}(61.8 \%$ to $66.1 \%)$, and EE (62.3\% to $66.9 \%$ ) in diets compared to pigs fed diets with $0.0 \%$ Yarrowia lipolytica.

\section{DISCUSSION}

This study showed that supplementation of Yarrowia lipolytica at a range of $1.5 \%$ and $3.0 \%$ is an effective fat supplement in nursery diets. Supplementing nursery diets with Yarrowia lipolytica at $1.5 \%$, replacing $0.8 \%$ poultry fat and $0.45 \%$ blood plasma, did not affect the growth performance, intestinal health and nutrient digestibility. Supplementing Yarrowia li-

Table 4. Intestinal health markers in the jejunal mucosa of pigs fed diets with Yarrowia lipolytica

\begin{tabular}{|c|c|c|c|c|c|}
\hline \multirow{2}{*}{ Item (\%) } & \multicolumn{3}{|c|}{ Treatment $^{1)}$} & \multirow{2}{*}{ SEM } & \multirow{2}{*}{ p-value } \\
\hline & YLO & YL1.5 & YL3 & & \\
\hline \multicolumn{6}{|c|}{ Proximal $^{2}$ jejunal mucosa, concentration/mg of protein } \\
\hline TNF-a $(p g)$ & 0.64 & 0.77 & 0.61 & 0.12 & 0.570 \\
\hline $\mathrm{IL}-8$ (ng) & 0.62 & 0.75 & 0.62 & 0.07 & 0.300 \\
\hline $\lg A(\mu g)$ & 1.45 & 1.52 & 1.55 & 0.17 & 0.918 \\
\hline $\lg G(\mu g)$ & 4.45 & 4.04 & 4.79 & 0.33 & 0.329 \\
\hline \multicolumn{6}{|c|}{ Distal jejunal mucosa, concentration/mg of protein } \\
\hline TNF-a $(p g)$ & 2.59 & 1.75 & 2.13 & 0.40 & 0.349 \\
\hline IL-8 (ng) & 1.12 & 0.79 & 1.16 & 0.22 & 0.370 \\
\hline $\lg A(\mu \mathrm{g})$ & 1.08 & 1.07 & 1.47 & 0.21 & 0.314 \\
\hline $\lg G(\mu \mathrm{g})$ & 4.64 & 4.21 & 5.99 & 0.67 & 0.174 \\
\hline
\end{tabular}

SEM, standard error of mean; TNF-a, tumor necrosis factor alpha; IL-8, interleukin-8; IgA, immunoglobulin A; IgG, immunoglobulin G.

1) The dietary treatments consisted of a basal diet supplemented with Yarrowia lipolytica at $0.0 \%, 1.5 \%$, and $3.0 \%$ as $\mathrm{YLO}, \mathrm{YL} 1.5$, and $\mathrm{YL} 3$, respectively.

2) Proximal: $1.5 \mathrm{~m}$ after the pyloric duodenal junction, distal: $1.5 \mathrm{~m}$ before the ileocecal junction. 
Table 5. Apparent ileal digestibility of nutrients in diets with fed to pigs Yarrowia lipolytica

\begin{tabular}{lccccc}
\hline \multirow{2}{*}{ Item (\%) } & \multicolumn{3}{c}{ Treatment $^{\text {1) }}$} & \multirow{2}{*}{ SEM } & p-value \\
\cline { 2 - 4 } & YL0 & YL1.5 & YL3 & & \\
\hline DM & $55.0^{\mathrm{a}}$ & $52.5^{\mathrm{ab}}$ & $40.2^{\mathrm{b}}$ & 4.1 & 0.045 \\
$\mathrm{GE}$ & $57.5^{\mathrm{a}}$ & $56.5^{\mathrm{a}}$ & $44.0^{\mathrm{b}}$ & 3.9 & 0.047 \\
$\mathrm{CP}$ & $66.1^{\mathrm{A}}$ & $61.8^{\mathrm{AB}}$ & $52.1^{\mathrm{B}}$ & 4.2 & 0.084 \\
$\mathrm{EE}$ & $66.9^{\mathrm{a}}$ & $62.3^{\mathrm{a}}$ & $50.8^{\mathrm{b}}$ & 3.4 & 0.011 \\
\hline
\end{tabular}

SEM, standard error of mean; DM, dry matter; GE, gross energy; CP, crude protein; $E E$, ether extract.

1) The dietary treatments consisted of a basal diet supplemented with Yarrowia lipolytica at $0.0 \%, 1.5 \%$, and $3.0 \%$ as YL0, YL1.5, and YL3, respectively.

a,b Within a row, means without a common superscripts letter are significant different $(p<0.05)$.

$A, B$ Within a row, means without a common superscripts letter are tended to be different $(p<0.10)$.

polytica at $3.0 \%$ replacing $1.6 \%$ poultry fat and $0.9 \%$ blood plasma did not adversely affect the growth performance of pigs, whereas it reduced the AID of DM, GE, CP, and EE. The current results are in agreement with previous studies that reported the supplementation of yeasts at 30\% in fish diets [13] and at 1.6×107 colony-forming unit/g of nursery diets [32] reduced the apparent digestibility of nutrients but did not affect the overall growth performance. Conversely, Czech et al [33] reported that supplementation of 3.0\% of Yarrowia lipolytica replacing soybean meal enhanced the growth performance of nursery pigs from 10 to $32 \mathrm{~kg}$. A reduction of nutrient digestibility with $3.0 \%$ of Yarrowia lipolytica without affecting the growth performance observed in this study is probably due to the bioactive compounds from yeasts including oleic acid, $\beta$-glucans and mannans that play important roles on microbiota modulation and immune system $[34,35]$.

The decreased nutrient digestibility observed in this study may be due to the complex structures from yeast cell walls that have negative effects on nutrient digestibility [22]. In this study, Yarrowia lipolytica was added to diets by replacing up to $1.6 \%$ poultry fat and $0.9 \%$ blood plasma. Considering that the Yarrowia lipolytica was not processed to lyse the cell wall prior the study, the cell wall may have partially protected the fat from digestion which may have contribute to reduce the EE digestibility [36]. Additionally, the protein in the Yarrowia lipolytica used in this study may have lower digestibility compared to blood plasma and consequently reduced the CP digestibility in feed with 3.0\% Yarrowia lipolytica. The yeast cell wall are fermented by the intestinal microbiota in the large intestine to produce short-chain fatty acids (SCFA) and, consequently, release cell components in the large intestine [37]. In addition to the cell wall compounds, the undigested nutrients are fermented by the intestinal microbiota along the intestine affecting the production SCFA and consequently affecting the energy utilization [38]. The majority microbial fermentation occurs in the cecum-colon portion [39], therefore, the SCFA produced during fermentation in the large intestine was not counted in the analysis of AID, although they could affect the growth performance even with reduced AID of nutrients [40]. Yeast cell wall is known for their effects on microbiota modulation of intestinal microbiota [37]. Kiros et al [41] showed that the increased relative abundance of Prevotella, an effective producer of SCFAs, in pigs fed diets with yeast had positive correlations with growth performance by increasing energy utilization. In addition, dietary mannans and $\beta$-glucans have been related to increased relative abundance of butyrate-producing bacteria including Clostridium [35] and Faecalibacterium prausnitzii [42]. Besides the energy metabolism, butyric acid is known as an important compound for the intestinal health status [43].

It is well known that supplementing blood plasma in nursery diets improves the growth performance of pigs [20]. Besides the highly digestible protein, $20 \%$ of protein in blood plasma is IgG that inhibit the adherence of antigens in the intestinal mucosa, enhancing the immune response and, consequently improving the growth performance [44]. Yarrowia lipolytica has a high concentration of oleic acid, which possesses anti-inflammatory and anti-oxidative properties [15] and, consequently, would enhance the health and growth performance of pigs. Similar to the immune modulating function of dietary blood plasma, $\beta$-glucans and mannans present in yeast cell wall are beneficial to animal growth and health [19]. The first mechanism of $\beta$-glucan and mannans is that both can bind to the carbohydrate receptors on pathogenic bacteria preventing infection by inhibiting the adherence of pathogens to the intestinal mucosa [32]. Secondly, they can be bind by receptors on intestinal epithelial cells, including $\mathrm{M}$ cells, macrophages and dendritic cells and, consequently activate the innate response to release cytokines and adoptive response [45]. Following the innate response, activated intestinal epithelial cells stimulate Th- 1 cells to reduce the production of pro-inflammatory cytokines, such as TNF- $\alpha$, IL-6, and IL-8 [34]. Li et al [18] described that the uptake of $\beta$-glucans from Saccharomyces cerevisiae at $50 \mathrm{mg} / \mathrm{kg}$ in nursery increased the release of the anti-inflammatory cytokine, IL-10, to inhibit the overproduction of proinflammatory cytokines, TNF- $\alpha$ and IL-6 in plasma under Escherichia coli challenge. In addition, supplementing Saccharomyces cerevisiae in pigs [46] enhanced immune system by promoting the concentrations of IgA and IgG in blood and resulted in improved growth performance. However, the immune markers measured in this study were not adversely affected by supplementing Yarrowia lipolytica up to 3.0\% indicating that the bioactive components from Yarrowia lipolytica may have similar effects as those expected from blood plasma [20] for maintaining animal growth and health. 
In conclusion, supplementing Yarrowia lipolytica at 1.5\% in diets successfully reduced $0.8 \%$ of poultry fat and $0.45 \%$ blood plasma, without affecting growth performance, intestinal health and nutrient digestibility in diets fed to nursery pigs. Moreover, supplementing Yarrowia lipolytica at 3.0\% replacing $1.6 \%$ poultry fat and $0.9 \%$ blood plasma in diets did not cause an adverse effect on growth performance and intestinal health possibly due to the benefits from oleic acid, $\beta$-glucans and mannans in Yarrowia lipolytica, whereas it reduced digestibility of nutrients in diets fed to nursery pigs.

\section{CONFLICT OF INTEREST}

We certify that there is no conflict of interest with any financial organization regarding the material discussed in the manuscript.

\section{FUNDING}

This study was supported by CJ Blossom Park Grant Proposal Competition Award (Suwon, South Korea) and North Carolina Agricultural Foundation (Raleigh, NC, USA).

\section{REFERENCES}

1. Lauridsen C, Bruun Christensen TB, Halekoh U, Jensen SK. Alternative fat sources to animal fat for pigs. Lipid Technol 2007;19:156-9. https://doi.org/10.1002/lite.200700051

2. Ball MEE, Magowan E, Beattie VE, et al. The effect of dietary energy source on performance and nutrient digestibility in growing pigs. J Anim Feed Sci 2010;19:408-17.

3. Sundaram TS, Giromini C, Rebucci R, Baldi A. Omega-3 polyunsaturated fatty acids counteract inflammatory and oxidative damage of non-transformed porcine enterocytes. Animals 2020;10:956. https://doi.org/10.3390/ani10060956

4. van Heugten E, Coffey MT, Spears JW. Effects of immune challenge, dietary energy density, and source of energy on performance and immunity in weanling pigs. J Anim Sci 1996;74:2431-40. https://doi.org/10.2527/1996.74102431x

5. Gatlin LA, See MT, Larick DK, Lin X, Odle J. Conjugated linoleic acid in combination with supplemental dietary fat alters pork fat quality. J Nutr 2002;132:3105-12. https://doi. org/10.1093/jn/131.10.3105

6. USDA. Oil crops yearbook [Internet]. USDA; 2021 [cited Year Month Day]. Available from: https://www.ers.usda. gov/data-products/oil-crops-yearbook/documentation/

7. Canakci M. The potential of restaurant waste lipids as biodiesel feedstocks. Bioresour Technol 2007;98:183-90. https:// doi.org/10.1016/j.biortech.2005.11.022

8. Mielke T. World markets for vegetable oils and animal fats. In: Biokerosene. In: Kaltschmitt M, Neuling U, editors. Biokerosene. Berlin, Heidelberg, Germany: Springer; 2018. p. 147-88. https://doi.org/10.1007/978-3-662-53065-8_8

9. Lindblom SC, Gabler NK, Kerr BJ. Influence of feeding thermally peroxidized soybean oil on growth performance, digestibility, and gut integrity in growing pigs. J Anim Sci 2018;96:558-69. https://doi.org/10.1093/jas/sky004

10. Blomqvist J, Pickova J, Tilami SK, et al. Oleaginous yeast as a component in fish feed. Sci Rep 2018;8:15945. https://doi. org/10.1038/s41598-018-34232-x

11. Benzertiha A, Kierończyk B, Rawski M, Kołodziejski P, Bryszak M, Józefiak D. Insect oil as an alternative to palm oil and poultry fat in broiler chicken nutrition. Animals 2019;9:116. https://doi.org/10.3390/ani9030116

12. Czech A, Merska-Kazanowska M, Całyniuk Z. Redox status, biochemical parameters and mineral elements content in blood of turkey hens fed a diet supplemented with Yarrowia lipolytica yeast and two bacillus species. Animals 2020;10: 459. https://doi.org/10.3390/ani10030459

13. Hatlen B, Berge GM, Odom JM, Mundheim H, Ruyter B. Growth performance, feed utilisation and fatty acid deposition in Atlantic salmon, Salmo salar L., fed graded levels of highlipid/high-EPA Yarrowia lipolytica biomass. Aquaculture 2012;364-365:39-47. https://doi.org/10.1016/j.aquaculture. 2012.07.005

14. Groenewald M, Boekhout T, Neuvéglise C, Gaillardin C, van Dijck PWM, Wyss M. Yarrowia lipolytica: Safety assessment of an oleaginous yeast with a great industrial potential. Crit Rev Microbiol 2014;40:187-206. https://doi.org/10.3109/ 1040841X.2013.770386

15. Rehman K, Haider K, Jabeen K, et al. Current perspectives of oleic acid: Regulation of molecular pathways in mitochondrial and endothelial functioning against insulin resistance and diabetes. Rev Endocr Metab Disord 2020;21:631-43. https://doi.org/10.1007/s11154-020-09549-6

16. Stewart GG. The structure and function of the yeast cell Wall, plasma membrane and periplasm. In: Brewing and distilling yeasts. The yeast handbook. Springer, Cham; 2017. p. 55-75. https://doi.org/10.1007/978-3-319-69126-8_5

17. Lipke PN, Ovalle R. Cell wall architecture in yeast: new structure and new challenges. J Bacteriol 1998;180:3735-40. https:// doi.org/10.1128/JB.180.15.3735-3740.1998

18. Li J, Xing J, Li D, et al. Effects of $\beta$-glucan extracted from Saccharomyces cerevisiae on humoral and cellular immunity in weaned piglets. Arch Anim Nutr 2005;59:303-12. https:// www.tandfonline.com/doi/full/10.1080/17450390500247832

19. Kogan G, Kocher A. Role of yeast cell wall polysaccharides in pig nutrition and health protection. Livest Sci 2007;109: 161-5. https://doi.org/10.1016/j.livsci.2007.01.134

20. Weaver AC, Campbell JM, Crenshaw JD, Polo J, Kim SW. Efficacy of dietary spray dried plasma protein to mitigate the negative effects on performance of pigs fed diets with corn naturally contaminated with multiple mycotoxins. J Anim Sci 2014;92:3878-86. https://doi.org/10.2527/jas.2013- 
6939

21. Peace RM, Campbell J, Polo J, Crenshaw J, Russell L, Moeser A. Spray-dried porcine plasma influences intestinal barrier function, inflammation, and diarrhea in weaned pigs. J Nutr 2011;141:1312-7. https://doi.org/10.3945/jn.110.136796

22. Holanda DM, Yiannikouris A, Kim SW. Investigation of the efficacy of a postbiotic yeast cell wall-based blend on newlyweaned pigs under a dietary challenge of multiple mycotoxins with emphasis on deoxynivalenol. Toxins (Basel) 2020;12: 504. https://doi.org/10.3390/toxins12080504

23. NRC. Nutrient requirements of swine. 11th rev. ed. Washington, DC, USA: National Academies Press; 2012.

24. Michalik B, Biel W, Lubowicki R, Jacyno E. Chemical composition and biological value of proteins of the yeast Yarrowia lipolytica growing on industrial glycerol. Can J Anim Sci 2014; 94:99-104. https://doi.org/10.4141/cjas2013-052

25. Guo JY, Phillips CE, Coffey MT, Kim SW. Efficacy of a supplemental candy coproduct as an alternative carbohydrate source to lactose on growth performance of newly weaned pigs in a commercial farm condition. J Anim Sci 2015;93:5304-12. https://doi.org/10.2527/jas.2015-9328

26. Duarte ME, Tyus J, Kim SW. Synbiotic effects of enzyme and probiotics on intestinal health and growth of newly weaned pigs challenged with enterotoxigenic F18+Escherichia coli. Front Vet Sci 2020;7:7-573. https://doi.org/10.3389/fvets. 2020.00573

27. Moita VHC, Duarte ME, da Silva SN, Kim SW. Supplemental effects of functional oils on the modulation of mucosa-associated microbiota, intestinal health, and growth performance of nursery pigs. Animals 2021;11:1591. https://doi.org/10. 3390/ani11061591

28. Myers WD, Ludden PA, Nayigihugu V, Hess BW. Technical Note: A procedure for the preparation and quantitative analysis of samples for titanium dioxide. J Anim Sci 2004;82:179-83. https://doi.org/10.2527/2004.821179x

29. Passos AA, Park I, Ferket P, Heimendahl E, Kim SW. Effect of dietary supplementation of xylanase on apparent ileal digestibility of nutrients, viscosity of digesta, and intestinal morphology of growing pigs fed corn and soybean meal based diet. Anim Nutr 2015;1:19-23. https://doi.org/10.1016/j.aninu. 2015.02.006

30. AOAC. Official methods of analysis. 18th ed. In: George J, Latimer W, editors. Gaithersburg, MD, USA: AOAC International; 2006.

31. Chen H, Zhang S, Kim SW. Effects of supplemental xylanase on health of the small intestine in nursery pigs fed diets with corn distillers' dried grains with solubles. J Anim Sci 2020;98: skaa185. https://doi.org/10.1093/jas/skaa185

32. van Heugten E, Funderburke DW, Dorton KL. Growth performance, nutrient digestibility, and fecal microflora in weanling pigs fed live yeast. J Anim Sci 2003;81:1004-12. https://doi.org/10.2527/2003.8141004x
33. Czech A, Smolczyk A, Grela ER, Kiesz M. Effect of dietary supplementation with Yarrowia lipolytica or Saccharomyces cerevisiae yeast and probiotic additives on growth performance, basic nutrients digestibility and biochemical blood profile in piglets. J Anim Physiol Anim Nutr (Berl). 2018;102: 1720-30. https://doi.org/10.1111/jpn.12987

34. Li J, Li DF, Xing JJ, Cheng ZB, Lai CH. Effects of $\beta$-glucan extracted from Saccharomyces cerevisiae on growth performance, and immunological and somatotropic responses of pigs challenged with Escherichia coli lipopolysaccharide. J Anim Sci 2006;84:2374-81. https://doi.org/10.2527/jas.2004541

35. Fouhse JM, Dawson K, Graugnard D, Dyck M, Willing BP. Dietary supplementation of weaned piglets with a yeastderived mannan-rich fraction modulates cecal microbial profiles, jejunal morphology and gene expression. Animal 2019;13:1591-8. https://doi.org/10.1017/S1751731118003361

36. Cruz A, Sterten H, Steinhoff FS, Mydland LT, Øverland M. Cyberlindnera jadinii yeast as a protein source for broiler chickens: effects on growth performance and digestive function from hatching to 30 days of age. Poult Sci 2020;99:316878. https://doi.org/10.1016/j.psj.2020.01.023

37. Duarte ME, Kim SW. Intestinal microbiota and its interaction to intestinal health in nursery pigs. Anim Nutr 2022;8:16984. https://doi.org/10.1016/j.aninu.2021.05.001

38. den Besten G, van Eunen K, Groen AK, Venema K, Reijngoud DJ, Bakker BM. The role of short-chain fatty acids in the interplay between diet, gut microbiota, and host energy metabolism. J Lipid Res 2013;54:2325-40. https://doi.org/10. 1194/jlr.R036012

39. Montagne L, Boudry G, Favier C, Huërou-Luron I, Lallès J, Sève B. Main intestinal markers associated with the changes in gut architecture and function in piglets after weaning. $\mathrm{Br}$ J Nutr 2007;97:45-57. https://doi.org/10.1017/S00071145072 0580X

40. Owusu-Asiedu A, Patience JF, Laarveld B, Van Kessel AG, Simmins PH, Zijlstra RT. Effects of guar gum and cellulose on digesta passage rate, ileal microbial populations, energy and protein digestibility, and performance of grower pigs. J Anim Sci 2006;84:843-52. https://doi.org/10.2527/2006.84 $4843 \mathrm{x}$

41. Kiros TG, Luise D, Derakhshani H, et al. Effect of live yeast Saccharomyces cerevisiae supplementation on the performance and cecum microbial profile of suckling piglets. Loor JJ, editor. PLoS One 2019;14:e219557. https://doi.org/10. 1371/journal.pone.0219557

42. Lo Verso L, Talbot G, Morissette B, et al. The combination of nutraceuticals and functional feeds as additives modulates gut microbiota and blood markers associated with immune response and health in weanling piglets. J Anim Sci 2020;98: skaa208. https://doi.org/10.1093/jas/skaa208

43. Louis P, Flint HJ. Diversity, metabolism and microbial ecology 
of butyrate-producing bacteria from the human large intestine. FEMS Microbiol Lett 2009;294:1-8. https://doi.org/10. 1111/j.1574-6968.2009.01514.x

44. Touchette KJ, Carroll JA, Allee GL, et al. Effect of spray-dried plasma and lipopolysaccharide exposure on weaned pigs: I. effects on the immune axis of weaned pigs. J Anim Sci 2002; 80:494-501. https://doi.org/10.2527/2002.802494x

45. Novak M, Vetvicka V. $\beta$-Glucans, history, and the present: immunomodulatory aspects and mechanisms of action. J Immunotoxicol 2008;5:47-57. https://doi.org/10.1080/154 76910802019045

46. Kiros TG, Derakhshani H, Pinloche E, et al. Effect of live yeast Saccharomyces cerevisiae (Actisaf Sc 47) supplementation on the performance and hindgut microbiota composition of weanling pigs. Sci Rep 2018;8:5315. https://doi.org/10. 1038/s41598-018-23373-8 